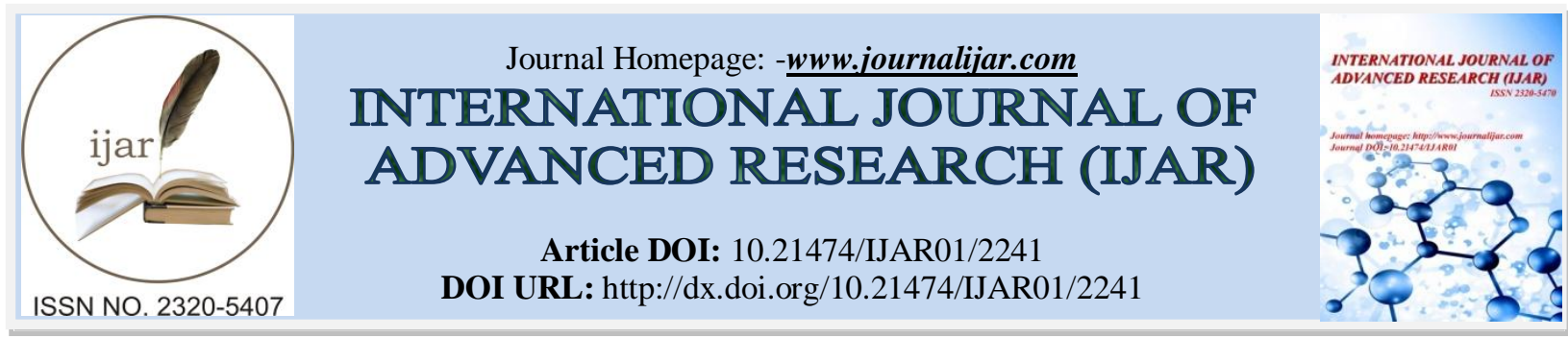

RESEARCH ARTICLE

\title{
STUDY OF BODE INDEX AND ITS COMPONENTS WITH PO2 AND PCO2 IN PATIENTS WITH COPD.
}

"Dr. Priti Meshram ${ }^{1}$, Dr. Nagsen N. Ramraje ${ }^{1}$, Dr. Pravin Tajane ${ }^{1}$ and Dr. Avinash R. Lamb ${ }^{2}$.

1. Department of Pulmonary Medicine, Grant Government Medical College and Sir J J Group of Hospitals, Byculla, Mumbai.

2. Department of Pulmonary Medicine, Government Medical College,Aurangabad, Maharashtra, India.

\section{Manuscript Info}

.........................

Manuscript History

Received: 29 September 2016

Final Accepted: 30 October 2016

Published: November 2016

\section{Abstract}

Chronic obstructive pulmonary disease is a disorder characterized by persistent airflow obstruction which is not fully reversible. The Body Mass Index, Airflow Obstruction, Dyspnea, Exercise Capacity- BODE Index was shown to be better than FEV1 at predicting risk of death among COPD patients. Increase in dead space and abnormalities in ventilation and perfusion impair oxygen uptake and carbon dioxide elimination in patients with COPD. This study aims to find an association between the BODE index, its components and $\mathrm{PO} 2$ and PCO2. Diagnosed cases of COPD were included in the study. All patients included were informed about the study protocol and a valid informed consent was taken. They underwent history taking, thorough clinical examination, Pulmonary Function tests, 6MWT and arterial blood gas analysis. Relation between BODE index and $\mathrm{PO} 2$ and $\mathrm{PCO} 2$ was more significant than relationship between FEV1 and PO2 and PCO2. Similarly, there was a positive correlation between 6MWD and $\mathrm{PO} 2$ and inverse correlation between 6MWD and PCO2. For dyspnea, there was a strong positive correlation with $\mathrm{PO} 2$ but only weak inverse correlation with PCO2. BMI had no significant correlation either with $\mathrm{PO} 2$ or PCO2. Multidimensional BODE index correlated best with oxygen uptake and carbon-dioxide elimination as compared to any of its components.

Copy Right, IJAR, 2016. All rights reserved.

\section{Introduction: -}

Chronic obstructive pulmonary disease is a disorder characterized by persistent airflow obstruction which is not fully reversible and associated with abnormal inflammatory response to noxious particles and gases ${ }^{1}$. The Spirometry derived parameter of FEV1 is simple and valid measurement of the degree of airflow obstruction and is often used as a surrogate for disease severity. COPD is a complex multidimensional disease and using degree of airflow obstruction alone to predict outcome has limitations. FEV1 is known to correlate poorly with patient's symptoms ${ }^{2}$.

The Body mass index, Airflowobstruction, Dyspnea, Exercise capacity - BODE INDEX - wasshown to be better than FEV1 at predicting risk of death among patients with $\mathrm{COPD}^{3}$. This multistage scoring system provides useful

Corresponding Author: -Dr. Priti Meshram.

Address: -Department of Pulmonary Medicine, Grant Government Medical College and Sir J J Group of Hospitals, Byculla, Mumbai. 
The effects of COPD on lung gas exchange are complex. The abnormalities in lung gas exchange for $\mathrm{O}_{2}$ and $\mathrm{CO}_{2}$ (i.e., increased dead-space volume and alveolar-arterial $\mathrm{O}_{2}$ gradient) require greater than normal levels of ventilation to maintain Eucapnia and Euoxia. Therefore, measurement of arterial blood gases is essential in patients with COPD to confirm degree of hypoxemia and hypercapnea. In patients with chronic airways obstruction, life expectancy is strongly dependent on the severity of blood gas abnormalities ${ }^{4}$. When significant hypoxaemia and hypercapnia are present, a majority of patients will die in a few years. Most commonly, $\mathrm{PO}_{2}$ is the measurement used to assess the effect of respiratory disease on oxygenation of arterial blood.The adequacy of $\mathrm{CO}_{2}$ elimination is measured by the partial pressure of $\mathrm{CO}_{2}$ in arterial blood, i.e., $\mathrm{PCO}_{2}$. There is broad relationship between Spirometry and blood gases in patients with COPD where $\mathrm{PaCO}_{2}$ rises when FEV1 falls below $1.5 \mathrm{~L}^{5}$.

This study aims to find out correlation of BODE index with $\mathrm{PO}_{2}$ and $\mathrm{PCO}_{2}$ in patients with COPD.

\section{Materials and Methods: -}

Adult patients diagnosed with COPD as per the GOLD guidelines were included in this study. The patients included in the study did not have any other Respiratory or known systemic co-morbidities.

All the patients underwent detailed history taking and clinical examination. All patients underwent Spirometry, 6 MWT and ABG analysis.

Patient's body mass index was calculated using formula-

Weight (kg)/height (meter) ${ }^{2}$.

Grade of dyspnea was classified as per Modified Medical Research Council Questionnaire.

The Six minute walk test was performed as per guidelines of $\mathrm{ATS}^{7}$. The BODE score was calculated as per Table $1^{3}$.

\section{Results: -}

The study included 50 COPD patients out of which $43(86 \%)$ were males and $7(14 \%)$ females. Mean age of the study group was 56.78 years. All patients were above 30 year and maximum (64\%) were in 50-70 years age group (Table 2).

Most of patients were with severe (50\%) and very severe (22\%) stage of COPD.

$46 \%$ patients had BMI greater than $21 \mathrm{~kg} / \mathrm{m}^{2}$ and $54 \%$ of the patients were with BMI less than or equal to $21 \mathrm{~kg} / \mathrm{m}^{2}$.

Most of the patients had Grade I (48\%) or Grade II (44\%) dyspnea.

Most patients 35 (70\%) were with FEV1 less than 50 (Percentage predicted). Mean FEV1 for patient group was $43.94 \pm 19.83$.

Mean six minute walk test distance of the study group was $329.52 \pm 96.18$. One patient was unable to complete the test due to dyspnea and distance covered was less than $149 \mathrm{~m}$.

BODE Index was categorized into four quartiles ${ }^{3}$.

Mean BODE Index of the study group was 3.76 \pm 1.93 .

Mean $\mathrm{PO}_{2}$ was $71.976 \pm 12.71 \mathrm{mmHg}$. Applying Pearson's correlation test, there was inverse correlation between BODE index and PO2 and it was statistically significant $(r=-0.782, \mathrm{P}<0.001)$. (Table 3, Figure 1 )

The mean $\mathrm{PCO}_{2}$ of patients was $39.67 \pm 7.25 \mathrm{mmHg}$. On applying Pearson's correlation test, there was a positive correlation between BODE index and PCO2 and was statistically most significant $(\mathrm{r}=0.570, \mathrm{P}<0.001)$. (Table 4 , Figure 2)

The mean FEV1 of patients was $43.94 \pm 19.83$ (\% Predicted). Applying Pearson's correlation test, there was positive correlation between FEV1 and PO2 and was statistically most significant $(r=0.695, \mathrm{P}<0.001)$ (Table 5).

Applying Pearson's correlation test, there was inverse correlation between FEV1 and PCO2 and statistically most significant $(\mathrm{r}=-0.476, \mathrm{P}<0.001)$ (Table 6$)$.

The mean 6MWT distance covered was $329.52 \pm 96.18$ m.Applying Pearson's correlation test, there was positive correlation between $6 \mathrm{MWD}$ (distance walked in 6 minutes) and PO2 and it was statistically significant $(\mathrm{r}=0.611, \mathrm{P}$ $<0.001)$ (Table 7). 
Applying Pearson's correlation test, there was inverse correlation between 6MWT(distance walked in six minutes) and PCO2 and it was statistically significant $(\mathrm{r}=-0.351, \mathrm{P}<0.05)$ (Table 8$)$.

The correlation between grades of dyspnea and $\mathrm{PO}_{2}$ and $\mathrm{PCO}_{2}$ was also studied. It was found that there was inverse correlation between grades of dyspnea and $\mathrm{PO}_{2}(\mathrm{r}=0.62, \mathrm{p}<0.0001)$, and direct but weak correlation between Grade of dyspnea and $\mathrm{PCO}_{2}(\mathrm{r}=0.25 \mathrm{p}=0.07)$ (Table 9).

Finally, the correlation between body mass index and $\mathrm{PO}_{2}$ and $\mathrm{PCO}_{2}$ was also studied. There was no significant correlation either with $\mathrm{PO}_{2}(\mathrm{p}=0.288)$ or $\mathrm{PCO}_{2}(\mathrm{p}=0.998)$ (Table 9).

\section{Discussion: -}

The diagnosis of COPD, classification of its severity, and progression of the disease can be monitored with Spirometry- a simple, non-invasive, and inexpensive test. The FEV1/FVC ratio, reflecting the rate of emptying of the lung, is used to define the presence of an obstructive ventilatory defect, commonly defined as a ratio less than 0.70 . Once airflow obstruction is established, the severity of the disease is classified by the reduction of FEV1 compared with a healthy reference population.

After COPD becomes clinically apparent, the median survival is about 10 years. The prognosis of COPD varies widely. This is because the disease has widely varying rates of progression and because death is often due to susceptibility to inter-current illness and other smoking related Illnesses such as lung cancer rather than progressive respiratory failure.

Several factors have been identified that predict poor survival in COPD. These include low FEV1, active smoking status, hypoxemia, poor nutrition, the presence of Cor pulmonale, resting tachycardia, low exercise capacity, severe Dyspnea, poor health-related quality of life, Anemia, frequent exacerbations, co-morbid illnesses, and low carbon monoxide diffusing capacity.

A multidimensional prognostic index that takes into account several indicators of COPD prognosis is the BODE index, which includes body mass index, obstructive ventilator defect severity, dyspnea severity, and exercise capacity. A BODE score greater than 7 is associated with a 30 percent 2-year mortality; whereas a score of 5 to 6 is associated with 15 percent 2-year mortality. If the BODE score is less than 5, the 2-year mortality is less than 10 percent ${ }^{8}$.

Measuring $\mathrm{PaO}_{2}$ and $\mathrm{PaCO}_{2}$ is the most important factor to determine the severity of COPD and draw an appropriate therapeutic approach. Patients in stable conditions can be expected on average to have an increased alveolar-arterial gradient for oxygen and a decrease in $\mathrm{PaO} 2$ due to the disease itself, and therefore to have lower $\mathrm{PaO} 2$ than comparable persons with healthy lungs. The worse the obstruction, the lower the oxygen and carbon dioxide exchange. In these patients, life expectancy is strongly dependent on the severity of blood gas abnormalities ${ }^{4}$. When significant hypoxemia and hypercapnia are present, majority of patients will die in a few years. The natural history of such patients in the later stages of disease, as $\mathrm{PaCO} 2$ begins to rise, is that FEV1 declines steadily and $\mathrm{PaO} 2$ declines slowly at first, then rather rapidly shortly before the patient dies.

Classification schemes that incorporate more parameters than degree of airflow obstruction are likely to predict outcome more accurately (Rennard 2004) ${ }^{9}$. It has been shown that - BODE INDEX to be better than FEV1 at predicting risk of death among patients with COPD (Celli et al 2004) ${ }^{3}$.

We have studied the correlation between BODE Index and severity of blood gas abnormalities $\left(\mathrm{PO}_{2}\right.$ and $\left.\mathrm{PCO}_{2}\right)$ as derangements in these will spell a poorer prognosis. There is strong correlation between BODE Index and $\mathrm{PO}_{2}(\mathrm{r}=-$ $0.782, \mathrm{P}<0.001)$ which is in inverse relation. There is also strong correlation between BODE Index and $\mathrm{PCO}_{2}(\mathrm{r}=$ $0.570, \mathrm{P}<0.001$ ) which is positive. A study was carried out by Mansour RahimiFard et $\mathrm{al}^{10}$ to study relationship between FEV1 and $\mathrm{PO}_{2}, \mathrm{PCO}_{2}$, in patients with COPD. The study concluded that a reliable equation could be established indicating a correlation between FEV1 and PO2 as well as PCO2 in patient with chronic bronchitis. In this study, they found that FEV1 had positive correlation with PO2 $(r=0.418, p<0.0001)$ inverse correlation with $\mathrm{PaCO} 2(\mathrm{r}=-0.533, \mathrm{p}<0.0001)$. In a study conducted by B. Delclaux et al ${ }^{16}$, there were significant correlations between blood gases and Spirometric parameters. $\mathrm{PaO}_{2}$ was positively correlated to $\mathrm{FEV1}(\mathrm{r}=0.268, \mathrm{p}<0.001)$. $\mathrm{PaCO}_{2}$ was negatively correlated to $\mathrm{FEV} 1(\mathrm{r}=0.358, \mathrm{p}<0.001)$. In patients with more severe impairment in blood 
gases $\left(\mathrm{PaO}_{2}<60 \mathrm{mmHg}\right.$ or $\left.\mathrm{PaCO}_{2} \geq 45 \mathrm{mmHg}\right)$ there was no correlation between FEV1 and $\mathrm{PaCO}_{2}$, and $\mathrm{PaO}_{2}$ was positively but weakly correlated to FEV1 ( $\mathrm{r}=0.14 ; \mathrm{p}<0.05)$.

In our study, we found that there was a strong positive correlation between FEV1 and $\mathrm{PO}_{2}(\mathrm{r}=0.695, \mathrm{P}<0.001)$ and inverse correlation with $\mathrm{PCO}_{2}(\mathrm{r}=-0.476, \mathrm{P}<0.001)$. This suggests that the more the obstruction, the lower the oxygenation and greater the hypercapnia.

Six-minute-walk test predictsthe risk of death in patients with COPD ${ }^{11}$. A study was conducted by V H F Mak ${ }^{12}$ et al to study the effect of arterial oxygen desaturation on Six minute walk distance, perceived effort, and perceived breathlessness in patients with airflow limitation. In this study, they found that baseline saturation before the walk correlated significantly with distance walked $(0.32, \mathrm{p}<0.01)$. In our study, we found that there is positive correlation between 6MWT and PO2 and which is statistically significant $(\mathrm{r}=0.611, \mathrm{P}<0.001)$ and there is negative significant correlation between 6MWT and PCO2 $(r=-0.351, \mathrm{P}<0.05)$.

Dyspnea represents the most disabling symptom of COPD; the degreeof dyspnea provides information regarding the patient's perceptionof illness and can be measured. Nishimura $\mathrm{K}$ et a ${ }^{13}$ conducted a study in which they followed a large cohort of patients with COPD, in which they used thethreshold values included in the BODE index, they found the score on theMMRC dyspnea scale was a better predictor of the risk of deaththan was the $\mathrm{FEV}_{1}$. In this study, patients were grouped on the grades of dyspnea and it was found that there were significant differences in $\mathrm{PO}_{2}$ and $\mathrm{PCO}_{2}$ between the groups. In our study, there was strong inverse correlation between dyspnea and $\mathrm{PO}_{2}(\mathrm{r}=0.62, \mathrm{p}<0.0001)$, and positive but weak correlation between dyspnea and $\mathrm{PCO}_{2}(\mathrm{r}=0.25, \mathrm{p}=0.07)$.

There was no significant correlation of Body Mass Index with either with $\mathrm{PO}_{2}(\mathrm{p}=0.288)$ or $\mathrm{PCO}_{2}(\mathrm{p}=0.998)$.

The study thus suggests that relationship between $\mathrm{BODE}$ index and $\mathrm{PO}_{2}$ and $\mathrm{PCO}_{2}$ is more significant than relationship between $\mathrm{FEV}_{1}$ and $\mathrm{PO}_{2}$ and $\mathrm{PCO}_{2}$. It has been shown that $\mathrm{FEV}_{1}$ does not adequately reflectall the systemic manifestations of the disease. For example,the $\mathrm{FEV}_{1}$ correlates weakly with the degree of dyspnea ${ }^{14}$ andthe change in $\mathrm{FEV}_{1}$ does not reflect the rate of decline in patients'health ${ }^{15}$. BODE Index, thus better correlates with arterial blood gas changes.

To conclude, BODE index relates more significantly with the oxygenation status of the patient then its individual components including $\mathrm{FEV}_{1}$.

Multidimensional BODE Index can be considered as a better index for reflecting arterial blood gas changes and thus severity of COPD than any other single parameter including FEV1. The study supports the view that the BODE index should be widely used in assessing COPD patients.

Scatter Diagram 1- BODE Index and PO2

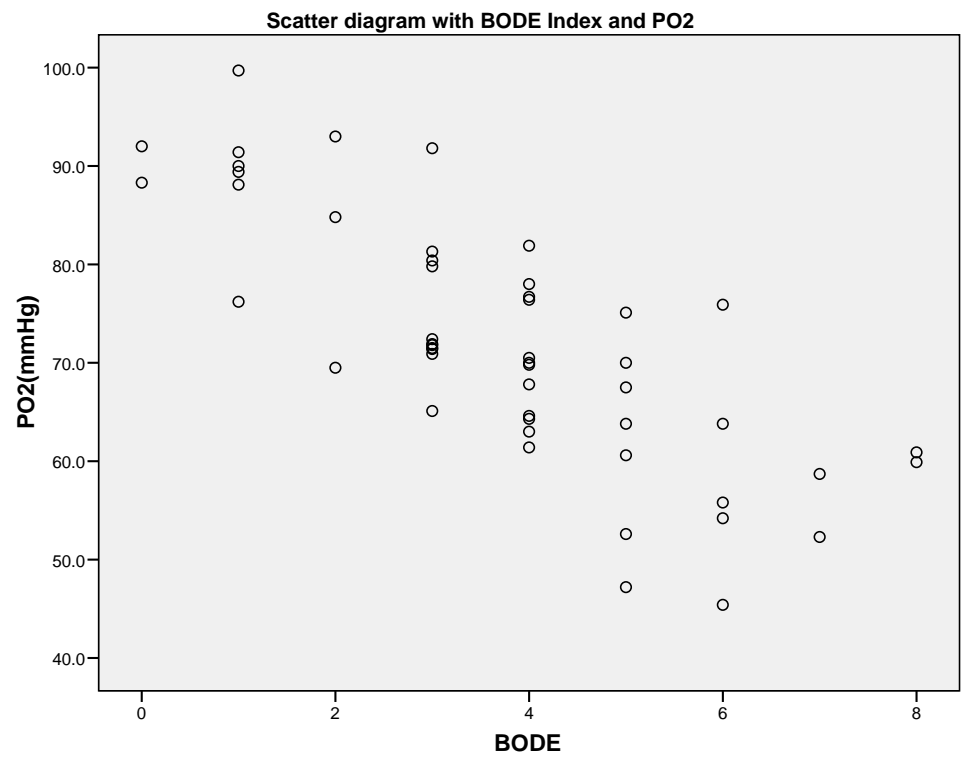


Scatter Diagram 2: BODE index with PCO2

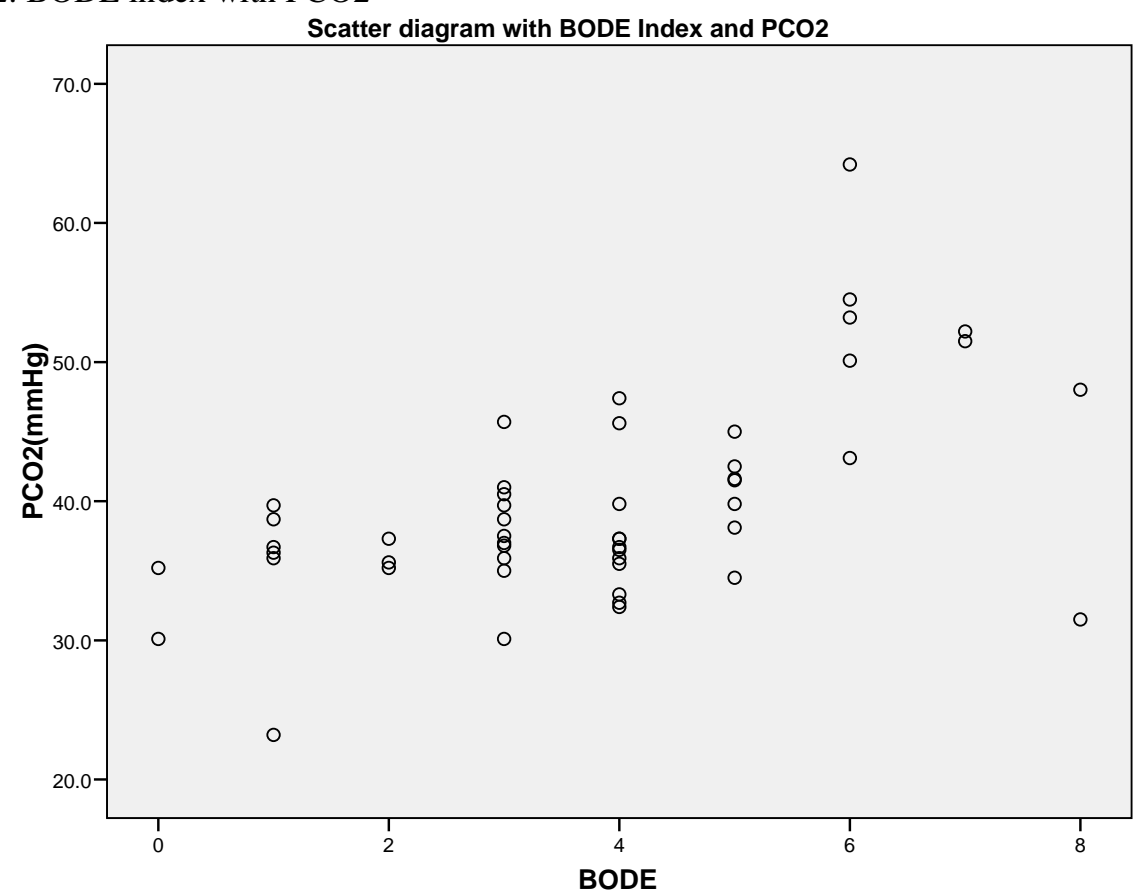

Table 1- BODE Index

\begin{tabular}{|l|l|l|l|l|}
\hline \multicolumn{4}{|l|}{ Points on the BODE Index } & $\mathbf{3}$ \\
\hline Variable & $\mathbf{0}$ & $\mathbf{1}$ & $\mathbf{2}$ & $<35$ \\
\hline FEV1(\% predicted) & $>65$ & $50-64$ & $36-49$ & $<149$ \\
\hline Distance walked in 6 min (meters) & $>350$ & $250-349$ & $150-249$ & 4 \\
\hline MMRC dyspnea scale & $0-1$ & 2 & 3 & \\
\hline Body-mass index (kg/M2) & $>21$ & $<21$ & & \\
\hline
\end{tabular}

BODE index was calculated as a sum of all the points from each row.

Table 2-Age and Sex distribution

\begin{tabular}{|l|l|l|l|l|}
\hline Age group (in years) & Males & Females & Total & Percentage(\%) \\
\hline $30-40$ & 2 & 0 & 2 & 4 \\
\hline $41-50$ & 7 & 1 & 8 & 16 \\
\hline $51-60$ & 15 & 4 & 19 & 38 \\
\hline $61-70$ & 11 & 2 & 13 & 26 \\
\hline $71-80$ & 7 & 0 & 7 & 14 \\
\hline $81-90$ & 1 & 0 & 1 & 2 \\
\hline Total & $43(86 \%)$ & $7(14 \%)$ & 50 & 100 \\
\hline
\end{tabular}

The study included 50 COPD patients out of whom 43(86\%) were males and 7(14\%) females. Mean age was 56.78 years. All patients were above 30 years and $64 \%$ were in 50-70 years age group.

Table 3- Correlation between BODE index and PO2:

\begin{tabular}{|l|l|l|l|}
\hline Indices & $\mathrm{N}$ & Mean & S.D. \\
\hline $\mathrm{BODE}$ & 50 & 3.76 & \pm 1.933 \\
\hline $\mathrm{PO}_{2}(\mathrm{mmHg})$ & 50 & 71.976 & \pm 12.7147 \\
\hline
\end{tabular}

$(\mathrm{r}=-0.782, \mathrm{p}<0.0001)$ 
Table 4- Correlation between BODE index and $\mathrm{PCO} 2$ :

\begin{tabular}{|l|l|l|l|}
\hline Indices & $\mathrm{N}$ & Mean & S.D. \\
\hline BODE & 50 & 3.76 & \pm 1.933 \\
\hline $\mathrm{PCO}_{2}(\mathrm{mmHg})$ & 50 & 39.670 & \pm 7.2529 \\
\hline
\end{tabular}
$(\mathrm{r}=0.570, \mathrm{p}<0.0001)$

Table 5- Correlation between FEV1 and PO2:

\begin{tabular}{|l|l|l|l|}
\hline Indices & $\mathrm{N}$ & Mean & S.D. \\
\hline FEV1 & 50 & 43.94 & \pm 19.832 \\
\hline $\mathrm{PO}_{2}(\mathrm{mmHg})$ & 50 & 71.976 & \pm 12.7147 \\
\hline
\end{tabular}
$(\mathrm{r}=0.695, \mathrm{p}<0.0001)$

Table 6-Correlation between FEV1 and PCO2

\begin{tabular}{|l|l|l|l|}
\hline Indices & $\mathrm{N}$ & Mean & S.D. \\
\hline FEV1 & 50 & 43.94 & \pm 19.832 \\
\hline $\mathrm{PCO}_{2}(\mathrm{mmHg})$ & 50 & 39.670 & \pm 7.2529 \\
\hline
\end{tabular}
$(\mathrm{r}=-0.476, \mathrm{p}<0.0001)$

Table-7-Correlation between 6MWT Distance (6MWD) and PO2

\begin{tabular}{|l|l|l|l|}
\hline Indices & $\mathrm{N}$ & Mean & S.D. \\
\hline $6 \mathrm{MWD}(\mathrm{m})$ & 50 & 329.52 & \pm 96.185 \\
\hline $\mathrm{PO}_{2}(\mathrm{mmHg})$ & 50 & 71.976 & \pm 12.7147 \\
\hline
\end{tabular}
$(\mathrm{r}=0.611, \mathrm{p}<0.0001)$

Table 8-Correlation between 6MWT Distance (6MWD) and PCO2

\begin{tabular}{|l|l|l|l|}
\hline Indices & $\mathrm{N}$ & Mean & S.D. \\
\hline $6 \mathrm{MWD}$ & 50 & 329.52 & \pm 96.185 \\
\hline $\mathrm{PCO}_{2}(\mathrm{mmHg})$ & 50 & 39.670 & \pm 7.2529 \\
\hline
\end{tabular}
$(\mathrm{r}=-0.351, \mathrm{p}=0.01)$

Table 9- Consolidated Significance Table

\begin{tabular}{|l|l|l|}
\hline Parameters & Correlation & Significance \\
\hline BODE index and PO2 & Inverse & $\begin{array}{l}\text { Statistically significant } \\
(\mathrm{r}=-0.782, \mathrm{p}<0.001) .\end{array}$ \\
\hline BODE index and PCO2 & Positive & $\begin{array}{l}\text { Statistically significant } \\
(\mathrm{r}=0.570, \mathrm{p}<0.001)\end{array}$ \\
\hline FEV1 and PO2 & Positive & $\begin{array}{l}\text { Statistically significant } \\
(\mathrm{r}=0.695, \mathrm{p}<0.001)\end{array}$ \\
\hline FEV1 and $\mathrm{PCO} 2$ & Inverse & $\begin{array}{l}\text { Statistically significant } \\
(\mathrm{r}=-0.476, \mathrm{p}<0.001) .\end{array}$ \\
\hline 6MWT distance and $\mathrm{PO} 2$ & Positive & $\begin{array}{l}\text { Statistically significant } \\
(\mathrm{r}=0.611, \mathrm{p}<0.001)\end{array}$ \\
\hline 6MWT distance and $\mathrm{PCO} 2$ & Inverse & $\begin{array}{l}\text { Statistically significant } \\
(\mathrm{r}=-0.351, \mathrm{p}<0.05) .\end{array}$ \\
\hline Grades of dyspnea and $\mathrm{PCO}_{2}$ & Inverse & $\begin{array}{l}\text { Statistically significant } \\
(\mathrm{r}=0.62, \mathrm{p}<00001),\end{array}$ \\
\hline Body mass index and $\mathrm{PO}_{2}$ & Weak positive & $\begin{array}{l}\text { Weak correlation } \\
(\mathrm{r}=0.25, \mathrm{p}=0.07) .\end{array}$ \\
\hline
\end{tabular}




\section{DECLARATION OF INTEREST: None \\ List of Figures:}

Figure 1: Scatter Diagram with BODE Index and PO2

Figure 2: Scatter Diagram with BODE Index and PCO2

\section{Bibliography:-}

1. GOLD COPD guidelines. 2017 updated 〈http:// www.goldcopd.com >

2. Mahler DA, Weinberg DH, Wells CK et al. The measurement of Dyspnea: contents, inter-observer agreement and physiological correlate of two new clinical indexes. Chest, 1984; 85:751-8.

3. Celli BR, Cote CG, Marin JM, et al: The body-mass index, airflow obstruction, Dyspnea, and exercise capacity index in Chronic Obstructive Pulmonary Disease. N Eng J Med, 2004; 350:1005-12.

4. Anthonisen NR, Wright EC, Hodgkin JE and the IPPB trial group. Prognosis in chronic obstructive pulmonary disease. Am Rev Respir Dis 1986; 133: 14-20.

5. Lane DJ, Howell JB, Giblin B Relation between airway obstruction and $\mathrm{CO}_{2}$ tension in COPD. Br Med J 1968, Sep 21;3(5620):707-709.

6. Besttall JC, Paul EA, Garrod R, Garnham R, Jones PW, Wedzicha JA. Usefulness of the Medical Reaserch Council (MRC) dyspnea scale as a measure of disability in patients with chronic obstructive pulmonary disease. Thorax 1999;54(7):581-6

7. ATS Statement: Guidelines for the Six-Minute Walk Test, American Journal of Respiratory and Critical Care Medicine (2002) Vol. 166. pp.111-117.

8. Robert A. Wise.Chronic Obstructive Pulmonary Disease: Clinical Course and Management; Fishman's Pulmonary Diseases and Disorders Fourth Edition: 729-746.

9. Rennard SI. Looking at the patient - approaching the problem of COPD. N Engl J Med.2004;350:965-6

10. Mansour RahimiFard, NahidZarezadeh. Relationship between FEV1 and $\mathrm{PaO} 2, \mathrm{PaCO} 2$ in Patients with Chronic bronchitis; Tanaffos 2004; 3(10): 41-46.

11. Gerardi DA, Lovett L, Benoit-Connors ML, Reardon JZ, ZuWallack RL.

12. Variables related to increased mortality following out-patient pulmonary Rehabilitation. EurRespir J 1996; 9:431-435.

13. V H F Mak, J R Bugler, C M Roberts, S G Spiro. Effect of Arterial oxygen desaturation on six minute walk distance, perceived effort, and perceived breathlessness in patients with airflow limitation. Thorax 1993; 48:3338.

14.Nishimura K, Izumi T, Tsukino M, Oga T. Dyspnea is a better predictor of 5-year survival than airway obstruction in patients with COPD. Chest 2002; 121:1434-1440 Mahler DA, Weinberg DH, Wells CK, Feinstein AR. The measurement of dyspnea: contents, inter-observer agreement, and physiologic correlates of two new clinical indices. Chest 1984; 85:751-758.

15. Burge PS, Calverley PM, Jones PW, Spencer S, Anderson JA, Maslen TK. Randomised, double blind, placebo controlled study of Fluticasone Propionate in patients with moderate to severe chronic obstructive Pulmonary disease: the ISOLDE trial. BMJ 2000; 320:1297-1303.

16. B. Delclaux, B. Orcel, B. Housset, W.A. Whitelaw, J-P. Derenne. Arterial Blood gases in elderly persons withchronic obstructive pulmonary diseases (COPD) EurRespir J, 1994; 7:856-861.Mansour Rahimi Fard , NahidZarezadeh ;Tanaffos 2004; 3(10): 41-46. 